\title{
Effect of Eight Weeks Caffeine Supplementation and High Fat Diet on PGC1- $\alpha$, Fndc-5 and UCP-1 Gene Expression in Male Wistar Rats
}

\author{
Nasser Ghanbari ${ }^{1}$ (D), Mohammad Rahman Rahimi ${ }^{1}$ (D), Sanaz Mahmazi ${ }^{2}$ (D), Mehdi Rahnema ${ }^{2}$ (D) \\ 1. Dept. of Exercise Physiology, Faculty of Human Sciences, University of Kurdistan, Sanandaj, Iran \\ 2. Dept. of Genetics, Faculty of Basic Sciences, Islamic Azad University, Zanjan Branch, Zanjan, Iran
}

\begin{tabular}{|c|c|}
\hline Article Info & ABSTRACT \\
\hline doi $10.30699 /$ jambs.29.136.271 & \multirow{2}{*}{$\begin{array}{l}\text { Background \& Objective: Today, obesity is one of the most important health } \\
\text { problems in the world. The purpose of this study was to determine the effects of } \\
\text { caffeine and high fat diet on expression of } P G C 1-\alpha, F n d c-5 \text { and } U C P-1 \text { genes in } \\
\text { male Wistar rats. }\end{array}$} \\
\hline $\begin{array}{l}\text { Received: 2020/07/23; } \\
\text { Accepted: 2021/03/14; }\end{array}$ & \\
\hline Published Online: 04 Apr 2021; & \multirow{3}{*}{$\begin{array}{l}\text { Materials \& Methods: To study the aim of this survey, } 40 \text { male Wistar rats were } \\
\text { divided into four equal groups ( } \mathrm{n}=10 \text { in each group), including: } 1 \text { ) control, 2) high fat } \\
\text { diet (HFD), 3) caffeine and } 4 \text { ) high fat diet and caffeine (HFD+caffeine) groups. Oral } \\
\text { gavage of caffeine was performed in a dose of } 6 \mathrm{mg} / \mathrm{kg} \text { body weight. PGC1- } \alpha \text { and } \\
\text { Fndc- } 5 \text { mRNA of muscles, and UCP- } 1 \mathrm{mRNA} \text { of subcutaneous fatty tissue were } \\
\text { measured using real-time polymerase chain reaction (qPCR). One-way ANOVA test } \\
\text { was used to analyze the data. }\end{array}$} \\
\hline $\begin{array}{l}\text { Use your device to scan and read the } \\
\text { article online }\end{array}$ & \\
\hline 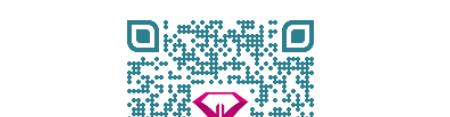 & \\
\hline 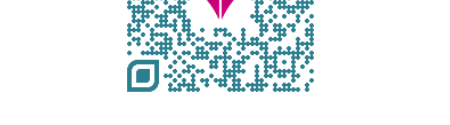 & $\begin{array}{l}\text { Results: The results of the present study showed that caffeine prevented overweight } \\
\text { and increased } P G C 1-\alpha, F n d c-5 \text { and } U C P-1 \text { gene expression in the caffeine group. } \\
\text { There were no significant differences in target genes expression, between the }\end{array}$ \\
\hline Corresponding Informa & \\
\hline $\begin{array}{l}\text { Nasser Ghanbari, } \\
\text { Dept. of Exercise Physiology, } \\
\text { University of Kurdistan, Sanandaj, Iran }\end{array}$ & $\begin{array}{l}\text { Conclusion: Based on our results, caffeine is a preventive factor for obesity. It can } \\
\text { increase the converting process of white adipose tissue to the brown. }\end{array}$ \\
\hline E-Mail: naser2617@gmail.com & Keywords: Caffeine, Adipose Tissue, PGC1- $\alpha$, FNDC-5 and UCP-1. \\
\hline (c) (i) (3) & its \\
\hline
\end{tabular}

\section{Introduction}

Obesity is one of the major problems in human societies causing many health disorders such as cardiovascular diseases, diabetes, respiratory and metabolic problems as well as some cancers and social psychiatric disorders (1). Studies have shown that over the past two decades, the prevalence of overweightness and obesity has increased in many countries around the world leading to economic consequences and rising health care costs.

Adipose tissue is among the tissues which are associated with obesity. Fat tissue is a key organ in regulating energy balance and weight. Adipose tissue in the human body is divided into two types, including white and brown adipose. White adipose tissue (WAT) stores extra energy of the homeostasis in the form of triglycerides. Brown adipose tissue (BAT) is a site for fat burning and energy consumption; it regulates thermogenesis (2).

Metabolically, brown cells are active and use lipids as an energy source in a process called non-vibrational thermogenesis (3). BAT regulates body temperature using energy dissipation through heat generation; it is specialized for thermogenesis (4). WAT can convert to
BAT or take on its characteristics; BAT is known as a therapeutic target for obesity. In fact, activation of BAT can also have beneficial metabolic effects on humans and may improve the consequences of obesity (5).

Proliferator-activated receptor gamma coactivator 1- $\alpha$ (PGC1- $\alpha$ ) is a factor produced during physical activity in the body. According to a study by Bostrom et al., the rats with high levels of PGC1- $\alpha$ were resistant to diabetes and age-related obesity (6). PGC1- $\alpha$ stimulates the secretion of substances from skeletal muscle, which affect other tissues function (6). One of the most important substances is Fibronectin type III domain-containing protein 5 (FNDC5). It is a membrane protein, which is broken down by proteolysis and released into the blood as irisin hormone.

In fact, $\mathrm{PGC}-1 \alpha$ is the activator for irisin secretion into the blood. Irisin induces uncoupling protein 1 (UCP-1). Due to increased lipolysis in the adipose tissue, irisin causes browning of subcutaneous and visceral adipose tissue, and increasing thermogenesis. Consequently, energy consumption increases and weight decreases (7). When irisin reaches the target cells, it induces the expression of UCP-1, and converts WAT to BAT (8). 
Non-vibrational heat exhaustion is the most important function of BAT. This function is regulated by $U C P-1$, which is located in the inner mitochondrial membrane, separating the electron transfer chain from energy production and thereby releasing potential energy in the form of heat (9).

Caffeine is a substance found in some foods and drinks. It has been shown that caffeine increases fat dependence in energy catabolism (10). Also, evidence demonstrate that the metabolic effects of caffeine at rest, lead to a temporary increase in calorie intake (11). If the effects of caffeine are related to energy consumption and metabolism increase, this substance is a secondary energy stimulator for people who want to control their weight.

Although some studies have shown that caffeine cause increase in fatty acid oxidation in long-term activity (10), other studies have not confirmed these results (12). The reasons of these inconsistencies in the results have not been fully elucidated. On the other hand, the amount of stored fat in human body in the form of triglycerides is higher in the obese people (13). Also, it has been shown that caffeine reduces adipose mass and increases insulin sensitivity (14) but the question is, what are the metabolic consequences of caffeine in people with different diets?

The present study aimed to answer the question whether caffeine can increase the expression of $P G C 1-\alpha, F N D C-5$ and $U C P-1$ in adipose and muscle tissues of rats with high fat diet, and prevent weight gain and obesity by turning WAT into BAT.

\section{Materials and Methods}

The experiments on animals (Rats) were done according to national guidelines (IR.UOK.REC. 1397.022), after approval from the Institutional Animal Ethics Committee. All protocols of the experiment were approved by the ethics committee of Kurdistan University.

In the first step, 40 male Wistar rats (age: 8 weeks) were purchased from Karaj Pasteur Institute. They weighed $180 \pm 45 \mathrm{~g}$. After a week of preparation in Animal Physiology Laboratory of Zanjan Islamic Azad University, randomly they were divided into four groups as follows: Control, high fat diet (HFD) (10 rats with HFD), caffeine (10 rats with caffeine) and HFD+caffeine (10 rats with HFD and caffeine). Rats were housed in polycarbonate cages for mouse maintenance. The storage environment condition was as follows: temperature of $22 \pm 3^{\circ} \mathrm{C}$ and humidity of $45 \pm 5 \%$ with $12 \mathrm{~h}$ light/dark cycle. Rats were kept in four-series cages.

Rats had ad libitum access to food and water. The experimental diet composition was based on Kim et al. formula (15). The normal diet included 5\% fat, 20.4\% proteins, $4.9 \%$ fibre, $65 \%$ carbohydrates, $3.8 \%$ salt mixture and $1.2 \%$ vitamin mixture. The HFD contained $24 \%$ carbohydrates, $46 \%$ fat, $20.4 \%$ proteins, $4.9 \%$ fiber, $3.8 \%$ salt mixture and $1.2 \%$ vitamin mixture $(15)$.
Diets were purchased from Company of Parsdam, Tehran, Iran. Rats in the HFD and HFD+caffeine groups were fed with HFD for eight weeks. The caffeine was also given to rats by gavage $6 \mathrm{mg} / \mathrm{kg}$ body weight/day (caffeine was purchased from Sigma Aldrich Company, USA). During the study, all ethics of working with laboratory animals were respected.

After passing the maintenance protocol, all groups were anesthetized in the same condition with xylazine (3-5 $\mathrm{mg} / \mathrm{kg}$ body weight) and ketamine (30-50 $\mathrm{mg} / \mathrm{kg}$ of body weight) (16). Then subcutaneous adipose tissue and twin muscle tissue of rats were taken. Rats were kept fasted for 12 hours before dissection, to prevent the effect of time on the level of hormones (circadian rhythm). They were killed alternately from quaternary groups. After dissection and sampling, the muscle and fat samples were washed with distilled water. They were placed in DNase and RNase free micro tubes containing liquid of RNA latter. They were kept in a $-80^{\circ} \mathrm{C}$ freezer for laboratory examination.

\section{Extraction of RNA}

Based on the instructions of manufacturer, $1 \mathrm{ml}$ of RNX (Sinaclon, Tehran, Iran) was poured on the samples, then, the samples were centrifuged, and incubated for five minutes in room temperature. Amount of $0.2 \mathrm{ml}$ chloroform was added to micro tubes and shaken well for 15 seconds. Subsequently, the samples were placed in ice at $4{ }^{\circ} \mathrm{C}$ for five minutes. The centrifuge was performed for 15 minutes with $12,000 \mathrm{rpm}$ at $4^{\circ} \mathrm{C}$. The aqueous phase was moved to another micro tube and an equal volume of isopropanol was added and mixed slowly, then incubated for 15 minutes in ice.

The mixture was centrifuged for 15 minutes with 12000 $\mathrm{rpm}$ at $4^{\circ} \mathrm{C}$. Supernatant was removed and $1 \mathrm{ml}$ of ethanol (75\%) was added, then gently vortexed to dislodge pellets from microtubule floor, and then centrifuged for 8 minutes at $7500 \mathrm{rpm}$ at $4^{\circ} \mathrm{C}$. The supernatant was discarded again and pellets were dried at room temperature. The pellets were dissolved in $50 \mu \mathrm{L}$ of diethylpyrocarbonate (DEPC) and incubated for 10 minutes at $55-60^{\circ} \mathrm{C}$.

RNA was inverse transcribed into cDNA, using a Takara cDNA Synthesis kit (Takara, Japan). To validate a subset of differentially expressed genes, quantitative real-time polymerase chain reaction (PCR) was used. Primer3 program was performed for gene-specific primer design (Information on primers is given in Table 1). Relative quantitative real time PCR was performed using the Amplicon SYBR Green PCR kit and a Qiagen thermal cycle (according to the protocol of manufacturer). Every run consisted of 15 minutes at $95^{\circ} \mathrm{C}$ followed by 40 cycles of 10 seconds at $95^{\circ} \mathrm{C}, 15$ seconds at $60^{\circ} \mathrm{C}$, and 20 seconds at $72^{\circ} \mathrm{C}$ in a real-time PCR machine.

In this study, all data fulfilled the parametric criteria. They were expressed as standard error average $( \pm$ SEM). Shapiro-Wilk test was used to investigate the natural distribution of data. In order to investigate the homogeneity of variances, Levene's test was used. 
One-way analysis of variance (ANOVA) test was applied to show the differences between the groups. If there was a significant difference, the Tukey's post hoc U test was used. SPSS 24 (SPSS Inc., Chicago, IL.,
USA) and Graph Pad Prism 8.4 were performed for analyzing the data. The level of statistical significance was set at $P$-value $\leq 05$.

Table 1. Primers

\begin{tabular}{cllcc} 
Gene Name & & Primers $\left(\mathbf{5}^{\prime} \rightarrow \mathbf{3}^{\prime}\right)$ & Length $(\mathbf{b} \mathbf{p})$ & Product size $(\mathbf{b} \mathbf{p})$ \\
\hline \multirow{2}{*}{ PGC1 } & Forward & TTGAAAAAGCTTGACTGGCGT & 21 & 94 \\
& Reverse & AGGGCAGCACACTCTATGTC & 20 & 103 \\
\multirow{2}{*}{ FNDC5 } & Forward & GTGGGCAGGTGTCATAGCTC & 20 & 20 \\
& Reverse & GCTGGTCTCTGATGCACTCT & 22 & 190 \\
\hline \multirow{2}{*}{ UCP1 } & Forward & AGTGCCACTGTTGTCTTCAGGG & 21 & \\
\hline
\end{tabular}

\section{Results}

No significant differences were found between the groups in terms of initial weight. After eight weeks, $11.7 \%$ weight gain was observed in the HFD group compared to the control $(p=0.411)$. However, average weight significantly decreased in the caffeine $(-29.75 \%)$ and HFD+caffeine group (-43.49\%) compared to the control $((P=0.001$ and $P=0.000$, respectively) (Table 2, Figure 1).
Final weight of caffeine $(-15.37 \%,(P=0.000))$ and HFD+caffeine groups $(-20.47 \%,(P=0.000))$ decreased compared to the HFD group. Comparing HFD+caffeine and caffeine groups, although there were not any significant differences, weight loss ($6.03 \%$ ) was observed in HFD+caffeine group, which means that caffeine is more effective when combined with an HFD (Table 2, Figure 1).

Table 2. Comparison of mean differences between group weights

\begin{tabular}{|c|c|c|c|c|c|}
\hline $\begin{array}{l}\text { Dependent } \\
\text { Variable }\end{array}$ & (I) Control & (J) Control & $\begin{array}{c}\text { Mean Difference } \\
\text { (I-J) }\end{array}$ & Std. Error & Sig. \\
\hline \multirow{12}{*}{ 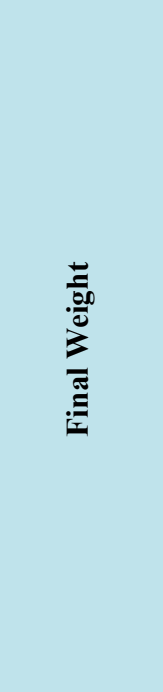 } & \multirow{3}{*}{ Control } & HFD & -13.20000 & 8.43918 & .411 \\
\hline & & Caffeine & $34.10000^{*}$ & 8.43918 & .001 \\
\hline & & HFD+Caffeine & $49.82500^{*}$ & 8.43918 & .000 \\
\hline & \multirow{3}{*}{ HFD } & Control & 13.20000 & 8.43918 & .411 \\
\hline & & Caffeine & $47.30000^{*}$ & 8.43918 & .000 \\
\hline & & HFD+Caffeine & $63.02500^{*}$ & 8.43918 & .000 \\
\hline & \multirow{3}{*}{ Caffeine } & Control & $-34.10000^{*}$ & 8.43918 & .001 \\
\hline & & HFD & $-47.30000^{*}$ & 8.43918 & .000 \\
\hline & & HFD + Caffeine & 15.72500 & 8.43918 & .262 \\
\hline & \multirow{3}{*}{ HFD+Caffeine } & Control & $-49.82500^{*}$ & 8.43918 & .000 \\
\hline & & HFD & $-63.02500^{*}$ & 8.43918 & .000 \\
\hline & & Caffeine & -15.72500 & 8.43918 & .262 \\
\hline
\end{tabular}

\section{PGC-1 $\alpha$ Expression}

There was a significant decrease in the expression of $P G C-1 \alpha$ in the HFD group, compared to the control
$(P=0.000,98.33 \%)$; however, a significant increase was observed in the caffeine group, $(P=0.000$, $280.8 \%$ ). In the HFD+caffeine group, no significant HFD+caffeine groups. 


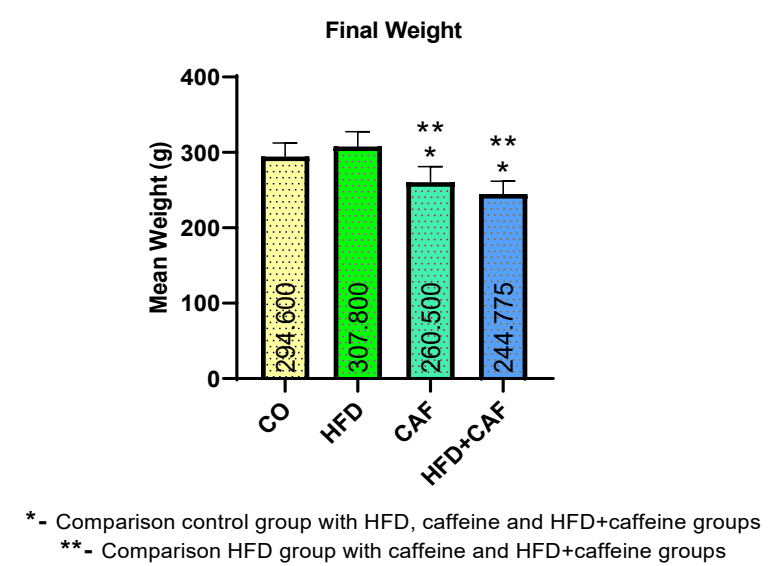

Figure 1. Final weight in the control, HFD, caffeine and HFD+caffeine groups.

\section{FNDC5}

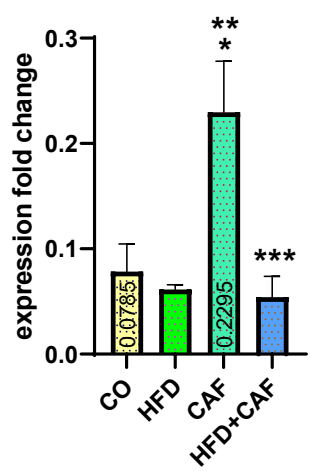

*- Comparison control with HFD, caffeine and HFD+caffeine group

**- Comparison HFD with caffeine and HFD+caffeine groups

***- Comparison coffeine with HFD+caffeine group

Figure 3. FNDC5 in the control, HFD, caffeine and HFD+caffeine groups.

\section{FNDC5 Expression}

According to Figure 3, the expression level of FNDC5 gene in the HFD group was not different compared to the control $(P=0.157,-19.7 \%)$. In the caffeine group, the expression level of FNDC5 was higher than control, significantly $(P=0.001,218.2 \%)$. In the HFD+caffeine group a significant decrease in the FNDC5 level was found, compared to the control $(P=0.051,22.4 \%)$ and caffeine group $(P=0.000$, $349.76 \%)$. There was a slight decrease in the HFD+caffeine group compared to the HFD group $(P=975,10.11 \%)$.

\section{UCP1 Expression}

According to Figure 4, UCP1 gene expression in the HFD group was not different significantly compared to the control $(P=0.337,15.2 \%)$. Also, there were not any differences between the caffeine and control group

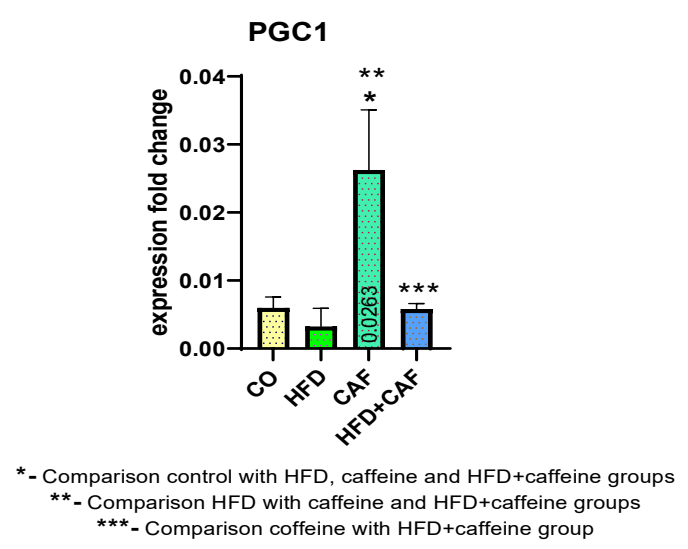

Figure 2. PGC-1 $\alpha$ in the control, HFD, caffeine and HFD+caffeine groups.

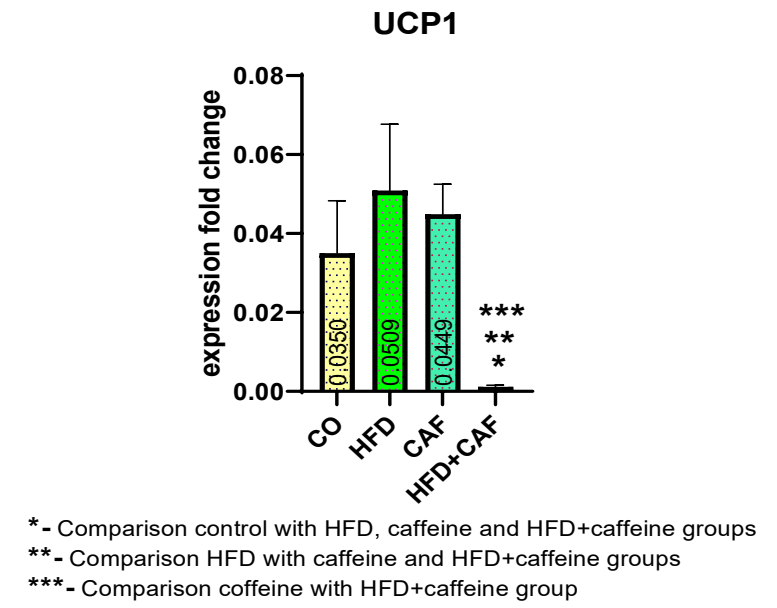

Figure 4. UCP1 in the control, HFD, caffeine and HFD+ caffeine groups.

$(P=0.451,12.1 \%)$. A significant decrease in the UCP1 level was observed in the HFD + caffeine group compared to the HFD $(\mathrm{P}=0.000,312.8 \%)$, control $(P=0.001,196 \%)$ and caffeine groups $(P=0.000$, $240.83 \%)$.

\section{Discussion}

The result of this study showed that HFD can increase weight of rats. As seen in Figure 1, the highest weight gain was observed in the HFD group. It is remarkable that weight gain was less in the caffeine consumer groups. In particular, despite the high-fat foods, the HFD+caffeine diet, did not increase the weight of rats as much as the HFD which seems to be due to caffeine consumption. Also, caffeine consumption caused weight gain in the caffeine group, 
but it was significantly less than the control group, indicating the effect of caffeine.

Although some previous studies have shown that HFD do not increase weight (17), the results of this study were indicative of weight gain in the HFD group. It was also greater than other groups. This finding has been observed in other studies, too (18). One of the probable reasons behind weight gain originated from HFD, is that it will lead to a positive fat balance, due to the imbalance caused by HFD between fat consumption and oxidation. HFD causes fat accumulation and leads to obesity (19).

One of the reasons caffeine seems to prevent obesity is related to energy intake. Caffeine can increase energy expenditure. In addition, it has been associated with a reduced incidence of diabetes and metabolic syndrome in the previous studies (20). The mechanism of this effect may be due to the high regulation of insulin-sensitive hormones such as adiponectin or improved uptake of glucose by the skeletal muscle (21).

In the present study, caffeine prevented weight gain in rats (Table 2). As seen, weight gain was higher in the groups, which did not consume caffeine. In fact, caffeine can prevent weight gain. It increases sympathetic tone of adipose tissue (22) and can cause release of great amounts of norepinepherine (NE) by stimulating the sympathetic post-synaptic nerves onto the richly innervated adipose tissue. This effect increases sympathetic stimulation of the body, so indirectly stimulates thermo-genesis and heat production.

Also, caffeine can enhance thermogenesis and cytoplasmic cAMP by preventing its destruction by phosphodiesterase (PDE) enzyme. On the other hand, caffeine is an adenosine receptor antagonist that can elevate cAMP levels in the adipose cells via preventing the inhibition of NE release by extracellular adenosine (23). Moreover, It has been suggested that caffeine consumption can elevate the metabolic rate and fat oxidation through fat cells lipolysis and catecholamines release (24).

As shown by Olcina, caffeine intake at a rate of 1 $\mathrm{mg} / \mathrm{kg}$, reduces respiratory exchange ratio (RER), referring to increased consumption of fat as a source of energy (25). Also, caffeine enhances adrenaline induced lipolysis in the fat cells and increases ephedrine in the blood. Eventually, it stimulates the release of fat into the blood and making the fat available as a fuel (26).

Consuming HFD significantly reduces $P G C-1 \alpha$ expression. As shown in Figure 2, expression of $P G C$ $1 \alpha$ in the HFD group reduced significantly. This finding is consistent with the research of El-Desoky et al.; however, according to the results of the HFD+caffeine group, caffeine prevents the negative effect of HFD. Another point is the significant increase in the caffeine group compared to the control group, which showed the positive effect of caffeine. Although caffeine was not able to increase the expression of PGC- $1 \alpha$ in the HFD+caffeine group, as much as the caffeine group, it neutralized the effects of high-fat foods and prevented the reduction of $P G C-1 \alpha$ expression.

AMP activated protein kinase (AMPK) is the main sensor of AMP level in the cells (27). Caffeine activates AMPK, which increases the expression of $P G C-1 \alpha$ gene in cells (28). PGC- $1 \alpha$ is a transcriptional activator and plays a key role in genes regulation involved in energy metabolism, thermogenesis and homeostasis.

$P G C-1 \alpha$ is activated by AMPK. AMPK does this by direct phosphorylation on two important residues, serine-538 and threonine. AMPK is a sensor to reduce the charge of energy in cells and also acts as a factor to decrease anabolic and increase catabolic reactions. It appears that caffeine can increase $P G C-1 \alpha$ expression through AMPK and activate signaling pathway of thermogenesis.

According to figure 3 , HFD significantly reduced the amount of FNDC5 expression in the HFD group. Caffeine was not able to reduce the negative effects of HFD (HFD+caffeine group). But significant increase of FNDC5 was observed in the caffeine group. PGC$1 \alpha$ increases fatty acid oxidation by interaction with many complexes including peroxisome proliferatoractivated receptor alpha (PPAR $\alpha)$ and cAMP receptor element binding (CREB) (29).

Since FNDC5 is one of target proteins of PGC1 $\alpha$, an increase in the expression of $P G C 1 \alpha$ can lead to increase in FNDC5 levels (8), as Bostrom et al. observed in their study (6). Also, other studies have reported that an increase in FNDC5, increases plasma irisin. Since FNDC5/irisin is responsible for activating BAT and thermogenesis (8), it activates the thermossensory signaling pathway by activating PGC1 $\alpha$.

Findings have shown that caffeine significantly increased UCP-1 compared to the control group. This is in line with a study by Bartelt et al. . They have also reported UCP1 increase due to the effect of caffeine; primary regulatory genes including $P P A R \gamma, P G C-1 \alpha$ and $P R$ domain containing 16 (PRDM16) also increased (30). Thus, it seems PGC-1 $\alpha$ increases expression of $U C P 1$ in cells but it is not able to make a significant increase in the HFD+caffeine group.

The transient receptor potential cation channels (TRPV) receptors can modulate thermogenesis of BAT; TRPV4 could be a down regulator of $P G C 1 \alpha$ (31). So, caffeine can induce more UCP1 and PGC1- $\alpha$ expression by antagonizing of TRPV4 (31). Even though, caffeine is an antagonist receptor of adenosine, it prevents phosphodiesterase and increases cell cAMP, which also activated by $\beta$-adrenergic stimulation (32). This could be the reason and mechanism behind the increased function of UCP1 by caffeine. 
Coupled to $\mathrm{G}$ proteins, beta-3 adrenergic receptor $(\beta 3-A R)$ induces cAMP, which in turn, activates protein kinase A. It stimulates fat hydrolysis and release of free fatty acids activating UCP1 (32). Adenylyl cyclase synthesizes cAMP from ATP, it binds positively to $\beta 3-\mathrm{AR}$, but is inhibited by the $\alpha 2$ adrenergic receptor $(A R \alpha 2)(33)$, which reduces with caffeine exposure.

Overall, a number of cases have supported the antilipid effect of caffeine, including morphological evidence of lipolysis and reduced caffeine-induced $A R \alpha 2$ gene suppression. Further studies are needed to learn more about the role of cAMP level in responding to the caffeine. However, according to the results of our study, caffeine consumption in association with HFD could not be effective on the expression of FNDC5 and $U C P 1$, in the HFD+caffeine group. It seems to be related to the body fat content of rats, as Westerterp et al. observed that fat oxidation decreases with increasing body fat percentage (34). Therefore, caffeine consumption is expected to be less effective on increasing fat oxidation in individuals with high body mass index(BMI) (35).

\section{Conclusion}

It seems that caffeine supplementation is more useful for people who want to prevent obesity and weight gain. In fact, caffeine can be used as a deterrent, but it is less useful in people with HFD, and who have high BMI. It can be explored in the future studies with different doses of caffeine.

\section{Acknowledgments}

This study was a PhD thesis in physical education (Biochemistry and metabolism). I would like to thank all those, who helped me in the preparation of this project, especially Dr. Rahman Rahimi, Dr. Sanaz Mahmazi, Dr. Mehdi Rahnama, and the staff of the laboratory of Zanjan Azad University.

\section{Conflict of Interest}

Authors declared no conflicts of interest.

\section{References}

1. Swinburn BA, Kraak VI, Allender S, et al. The global syndemic of obesity, undernutrition, and climate change: the Lancet Commission report. The Lancet. 2019;393(10173):791-846. [DOI: 10.1016/S0140-6736(18)32822-8]

2. Lo KA, Sun L. Turning WAT into BAT: a review on regulators controlling the browning of white adipocytes. Biosci Report. 2013;33:(5). e00065 [DOI:10.1042/BSR20130046]

3. Norouzirad R, González-Muniesa P, Ghasemi A. Hypoxia in obesity and diabetes: potential therapeutic effects of hyperoxia and nitrate. Oxid Med Cell Longev. 2017;2017: 5350267. [DOI:10.1155/2017/5350267]

4. Gesta S, Tseng YH, Kahn CR. Developmental origin of fat: tracking obesity to its source. Cell. 2007;131(2):242-56. [DOI:10.1016/j.cell.2007.10.004]

5. Peirce V, Vidal-Puig A. Regulation of glucose homoeostasis by brown adipose tissue. The lancet Diabet Endocrinol. 2013;1(4):353-60. [DOI: 10.1016/S2213-8587(13)70055-X]

6. Boström P, Wu J, Jedrychowski MP, et al. A PGC1- $\alpha$-dependent myokine that drives brownfat-like development of white fat and thermogenesis. Nature. 2012;481(7382):463-8. [DOI:10.1038/nature10777]

7. Shanshan Gao F, Li H, Huang Y, Liu Y, Chen Y. Effects and molecular mechanism of GSTIrisin on lipolysis and autocrine function in T3-L1 adipocytes. PLoS ONE. 11(1):e0147480 [DOI:10.1371/journal.pone.0147480]

8. Panati K, Suneetha Y, Narala V. Irisin/FNDC5An updated review. Eur Rev Med Pharmacol Sci. 2016;20(4):689-97.

9. Alberdi G, Rodríguez VM, Miranda J, Macarulla MT, Churruca I, Portillo MP. Thermogenesis is involved in the body-fat lowering effects of resveratrol in rats. Food Chem. 2013;141(2):1530-5. [DOI:10.1016/j.foodchem.2013.03.085]

10. Grgic J, Mikulic P, Schoenfeld BJ, Bishop DJ, Pedisic Z. The influence of caffeine supplementation on resistance exercise: A review. Sport Med. 2019;49(1):17-30. [DOI: 10.1007/s40279-018-0997-y]

11. Keisler BD, Armsey TD. Caffeine as an ergogenic aid. Curr Sport Med Report. 2006;5(4):215-9. [DOI: 10.1097/01.CSMR.0000306510.57644 .a7]

12. DeSisso TD, Gerst JW, Carnathan PD, et al Effect of caffeine on metabolic and cardiovascular responses to submaximal exercise: Boys Versus Men2429 2: 00 PM-2: 15 PM. Med Sci Sport Exercise. 2005;37(5):S465. [DOI: 10.1249/00005768-20050500102429]

13. Goodpaster BH, Theriault R, Watkins SC, Kelley DE. Intramuscular lipid content is increased in obesity and decreased by weight 
loss. Metabolism. 2000;49(4):467-72. [DOI: 10.1016/S0026-0495(00)80010-4]

14. Matsuda Y, Kobayashi M, Yamauchi R, et al. Coffee and caffeine improve insulin sensitivity and glucose tolerance in C57BL/6J mice fed a high-fat diet. Biosci, Biotechnol, Biochem. 2011;75(12):2309-15

[DOI: 10.1271/bbb.110452]

15. Kim JH, Hahm DH, Yang DC, Kim JH, Lee HJ, Shim I. Effect of crude saponin of Korean Red Ginseng on high fat diet-induced obesity in the rat. J Pharmacol Sci. 2005:0501140017. [DOI:10.1254/jphs.FP0040184]

16. Tam BT, Pei XM, Yung BY, et al. Unacylated ghrelin restores insulin and autophagic signaling in skeletal muscle of diabetic mice. Arch Europ J Physiol. 2015;467(12):2555-69. [DOI:10.1007/s00424-015-1721-5]

17. Chen WP, Ho BY, Lee CL, Lee CH, Pan TM. Red mold rice prevents the development of obesity, dyslipidemia and hyperinsulinemia induced by high-fat diet. Int $\mathrm{J}$ Obesit. 2008;32(11):1694-704. [DOI: 10.1038/ijo.2008.156]

18. Rahman HA, Sahib NG, Saari N, et al. Antiobesity effect of ethanolic extract from Cosmos caudatus Kunth leaf in lean rats fed a high fat diet. BMC Complement Alternat Med. 2017;17(1):122. [DOI:10.1186/s12906-0171640-4]

19. Picchi MG, Mattos AMd, Barbosa MR, et al. A high-fat diet as a model of fatty liver disease in rats. Acta cirurgica brasileira. 2011;26:25-30. [DOI: 10.1590/S0102-86502011000800006]

20. Takami H, Nakamoto $M$, Uemura $H$, et al. Inverse correlation between coffee consumption and prevalence of metabolic syndrome: baseline survey of the Japan multi-institutional collaborative cohort (J-MICC) study in Tokushima, Japan. J Epidemiol. 2013;23(1):1220. [DOI:10.2188/jea.JE20120053]

21. Kobayashi M, Matsuda Y, Iwai H, et al. Coffee improves insulin-stimulated Akt phosphorylation in liver and skeletal muscle in diabetic KK-Ay mice. J Nutr Sci Vitaminol. 2012;58(6):408-14.

[DOI: 10.3177/jnsv.58.408]

22. Huvanandana J, Thamrin C, McEwan AL, Hinder M, Tracy MB. Cardiovascular impact of intravenous caffeine in preterm infants. Acta Paediatrica. 2019;108(3):423-9. [DOI:10.1111/apa.14382]

23. Baalash A, Shafik NM, Abo Zeid AA, Ebeid AM. Effects of caffeine intake on oxido/inflammatory axis in rat model of non- alcoholic fatty liver disease. Bullet Egypt Soc Physiol Sci. 2017;37(1):45-58. [DOI:10.21608/besps. 2017.8225]

24. Yehya N. Mechanism, efficacy, and safety of an ephedrine, caffeine, and aspirin combination in the treatment of obesity. Nutr Bytes. 2001;7(1).

25. Olcina GJ, Muñoz D, Timón R, et al. Effect of caffeine on oxidative stress during maximum incremental exercise. J Sport Sci Med. 2006;5(4):621.

26. Bruce CR, Anderson ME, Fraser SF, et al. Enhancement of 2000-m rowing performance after caffeine ingestion. Med Sci Sport Exercise. 2000;32(11):1958-63. [DOI: 10.1097/00005768-20001100000021]

27. Lanzi CR, Perdicaro DJ, Tudela JG, et al. Grape pomace extract supplementation activates FNDC5/irisin in muscle and promotes white adipose browning in rats fed a high-fat diet. Food \& Func. 2020;11(2):1537-46. [DOI: 10.1039/C9FO02463H]

28. El-Desoky F, Gaber AE-H, Holah NS, et al. Protective effect of caffeine and curcumin versus silymarin on nonalcoholic steatohepatitis in rats. Menoufia Med J. 2020;33(1):196. [DOI:10.4103/mmj.mmj 253 18]

29. Lin JD. Minireview: the PGC-1 coactivator networks: chromatin-remodeling and mitochondrial energy metabolism. Molec Endocrinol. 2009;23(1):2-10. [DOI:10.1210/me.2008-0344]

30. Bartelt A, Heeren J. Adipose tissue browning and metabolic health. Nature Rev Endocrinol. 2014;10(1):24.

\section{[DOI:10.1038/nrendo.2013.204]}

31. Ye $\mathrm{L}$, Kleiner $\mathrm{S}, \mathrm{Wu} \mathrm{J}$, et al. TRPV4 is a regulator of adipose oxidative metabolism, inflammation, and energy homeostasis. Cell. 2012;151(1):96-110.

[DOI: 10.1016/j.cell.2012.08.034]

32. Cannon B, Nedergaard J. Brown adipose tissue: function and physiological significance. Physiol Rev. 2004;84(1):277-359. [DOI:10.1152/physrev.00015.2003]

33. Lafontan M, Barbe $\mathrm{P}$, Galitzky $\mathrm{J}$, et al. Adrenergic regulation of adipocyte metabolism. Human Reproduct. 1997;12(suppl_1):6-20. [DOI:10.1093/humrep/12.suppl 1.6] ]

34. Schutz Ya, Flatt J, Jéquier E. Failure of dietary fat intake to promote fat oxidation: a factor favoring the development of obesity. Am J Clin Nutr. 1989;50(2):307-14. [DOI: 10.1093/ajen/50.2.307] 
35. Hursel R, Viechtbauer W, Dulloo AG, et al. The effects of catechin rich teas and caffeine on energy expenditure and fat oxidation: a metaanalysis. Obesit Rev. 2011;12(7):e573-e81. [DOI:10.1111/j.1467-789X.2011.00862.x]

\section{How to Cite This Article:}

Ghanbari N, Rahimi M R, Mahmazi S, Rahnema M. Effect of Eight Weeks Caffeine Supplementation and High Fat Diet on PGC1- $\alpha$, Fndc-5 and UCP-1 Gene Expression in Male Wistar Rats. J Adv Med Biomed Res. 2021; 29 (136) :271-278

\section{Download citation:}

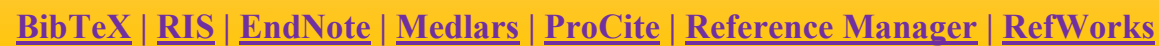

\section{Send citation to:}

(83. Mendeley 2 Zotero i) RefWorks RefWorks 